\title{
Cestode fauna of feral pigeons in Thessaloniki; Northern Greece
}

\author{
A. DIAKOU, S. PTOCHOS, E. PAPADOPOULOS* \\ Laboratory of Parasitology and Parasitic Diseases; Faculty of Veterinary Medicine; Aristotle University \\ of Thessaloniki, 54124 Thessaloniki Greece; *E-mail: eliaspap@vet.auth.gr
}

\begin{abstract}
Summary
The common pigeon (Columba livia) is adapted to a variety of habitats; including big cities and rural areas everywhere in the world. Several studies confirm that feral pigeons pose a considerable health risk to the livestock and human population. They may serve as a reservoir for several pathogenic agents that can be transmitted to poultry; wildlife; domesticated pets and humans. The aim of this survey was to investigate the cestode species present in feral pigeons in Thessaloniki; Northern Greece. A total of 136 adult feral pigeons were necropsied and the cestodes recovered were preserved for identification using morphological keys. Ninety-six $(70.58 \%)$ of them were found to be infected with cestode parasites; which were identified to be Raillietina spp.: $84(61.76 \%)$ were infected with $R$. echinobothrida; $20(14.7 \%)$ with $R$. cesticillus and 8 $(5.88 \%)$ with $R$. tetragona. Single infection was recorded in 80 birds ( $83.3 \%$ of the infected population); while a significantly lower number; i.e. 16 birds (16.7\%); had a mixed infection with $R$. echinobothrida and $R$. cesticillus $(p \leq 0.05)$. The current study confirms that feral pigeons in Northern Greece are heavily infected with cestode parasites. Therefore; it was concluded that feral pigeon management programmes and public education should be implemented to reduce the risk of a pigeon-to-human or livestock transmission of pathogenic agents and parasites in the country.
\end{abstract}

Keywords: Raillietina spp.; cestodes; pigeons; feral; Greece

\section{Introduction}

The common pigeon or rock pigeon (Columba livia) is found almost everywhere in the world. It is adapted to a variety of habitats, including big cities and rural areas and can travel long distances, being a strong flyer. Pigeons feed on a wide range of food items, such as grains, slugs, earth- worms, insects etc, which in many instances may carry parasitic infective stages (Ghazi et al., 2002; Kozhokov, 2007; Adang et al., 2008, 2009). Several studies exist in the literature confirming that feral pigeons pose considerable health risk to livestock and human population. They may serve as a reservoir for several pathogenic agents that can be transmitted to domestic animals, wildlife, and humans via their excreta, secretions, or dust from feathers. Some pathogenic agents can be also transmitted by consumption of infected pigeons. In addition, they are source of antigens causing allergic diseases (Haag-Wackernagel et al., 2010).

Very little information is available for the parasite fauna of wild birds and no recent data exist for feral pigeons in Greece. The aim of this survey was to investigate the cestode genera present in feral pigeons in Thessaloniki, Northern Greece.

\section{Materials and methods}

A total of 136 adult feral pigeons from the area of Thessaloniki were necropsied according to standard procedures. The digestive tract was removed, cut longitudinally to expose its content and examined under a stereoscope. The cestodes recovered from the small intestine were preserved into vials containing glycerine in alcohol $80^{\circ}(1: 17 \mathrm{v} / \mathrm{v})$ for identification using morphological keys provided by Yamaguti (1959), Soulsby (1982) and Khalil et al. (2006). T-test was used to compare the number of birds with single and mixed infections. The level of significance was set at $p \leq 0.05$.

\section{Results}

Out of the 136 pigeons examined, $96(70.58 \%)$ were infected with cestode parasites, which were identified to be Raillietina spp. More precisely, $84(61.76 \%)$ pigeons were infected with $R$. echinobothrida, $20(14.7 \%)$ with $R$. cesti- 


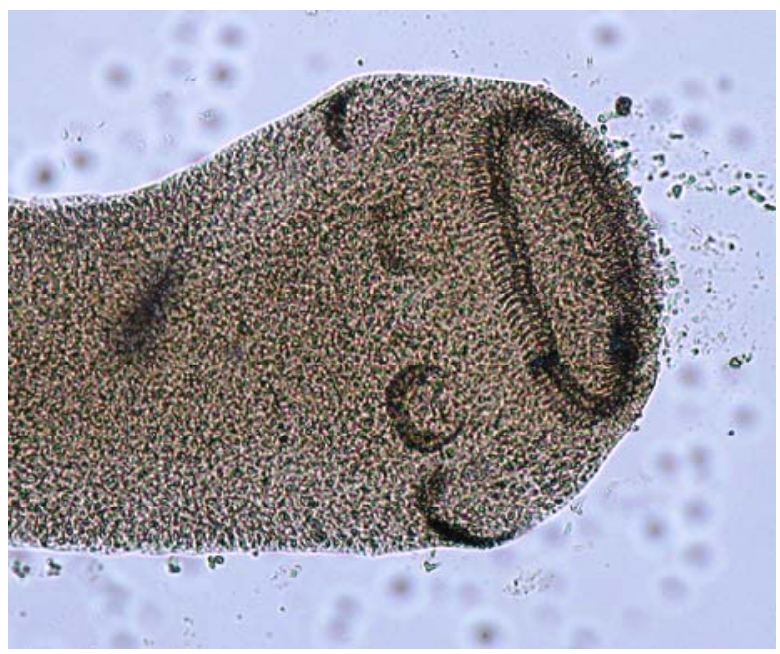

Fig. 1. The rostellum of a Raillietina echinobothrida tapeworm of the common pigeon (Columba livia)

cillus and $8(5.88 \%)$ with $R$. tetragona. Single infection was recorded in 80 birds $(83.3 \%$ of the infected population), while a significantly lower number, i.e. 16 birds $(16.7 \%)$, had a mixed infection with $R$. echinobothrida and $R$. cesticillus ( $p \leq 0.05$ ).

$R$. echinobothrida has a rostellum with 200 hooks, $10-$ $13 \mu \mathrm{m}$ long, in two rows and armed suckers with $8-10$ rows of hooks (Fig. 1). R. cesticillus bears a wide rostellum armed with $400-500$ small hooks, while the suckers are unarmed (Fig. 2). R. tetragona has a rostellum with only one row of minute hooks, $6-8 \mu \mathrm{m}$ long and the suckers are oval in shape armed with $8-10$ rows of small hooks, half the size of the ones found in $R$. echinobothrida (Fig. 3). A typical Raillietina spp. egg capsule is shown in Fig. 4.

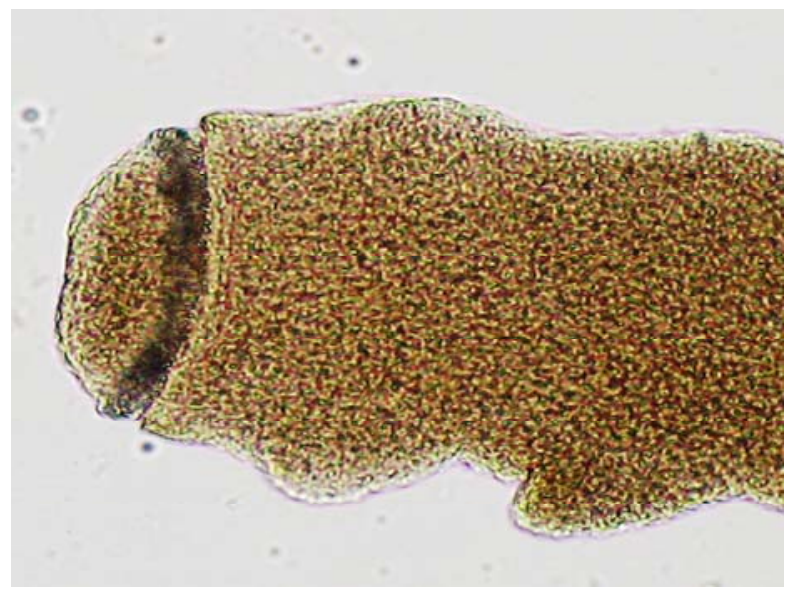

Fig. 2. The rostellum of a Raillietina cesticillus tapeworm of the common pigeon (Columba livia)

\section{Discussion}

The current study confirms that feral pigeons in Northern Greece are heavily $(70.58 \%)$ infected with cestode parasites. It is expected wild or feral birds to be infected with parasites, since they feed in different places by travelling long distances and their diet largely contains intermediate/paratenic hosts of tapeworms, such as earthworms, snails, ants etc.

All the cestodes identified in the pigeons of this study belonged to the genus Raillietina. This comes in good agreement with similar studies in other parts of the world, reporting that the most common among the internal parasites of the rock pigeon are the gut-tape worms of the genus Raillietina (Dede and Richards, 1998; Ghazi et al., 2002; Dehlawi 2006; Adang et al., 2008). However, in a previous survey carried out in Greece, including several avian wildlife species, Raillietina spp. was detected only in one common buzzard (Buteo buteo) out of the 33 necropsied birds of this species (Papazachariadout al., 2008). This tapeworm has a cosmopolitan distribution and is of major clinical importance for poultry. Heavy infections with Raillietina spp. tend to cause blockage of the gut of the host bird with secondary interactions causing damage to the intestinal tissues and contribute to nutrient depletion (Ghazi et al., 2002).

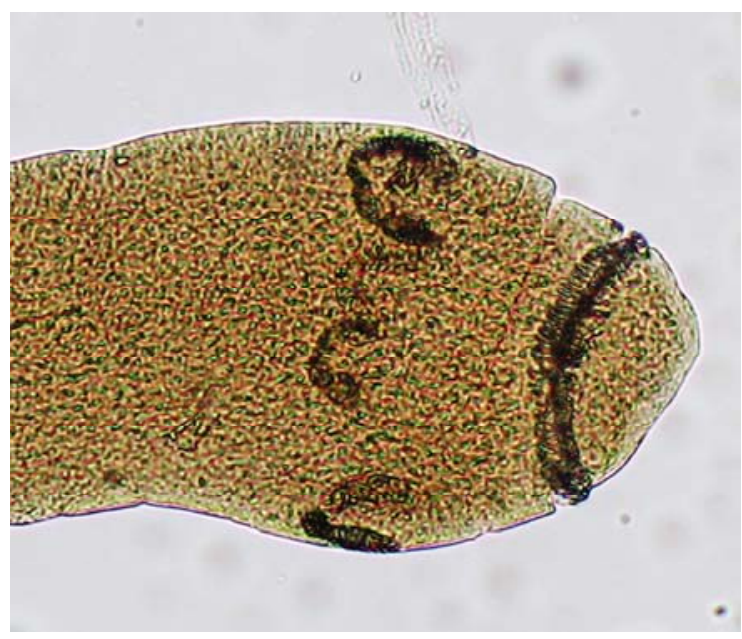

Fig. 3. The rostellum of a Raillietina tetragona tapeworm of the common pigeon (Columba livia)

Significantly higher number of the infected birds had single infection $(\mathrm{p} \leq 0.05)$, i.e. 80 birds $(83.3 \%$ of the infected population), compared to the ones that had a mixed infection with $R$. echinobothrida and $R$. cesticillus, i.e. 16 birds (16.7\%), while no triple infection was recorded. Adang et al. $(2008,2009)$ also recorded in a similar study that single infection was higher than mixed ones. Therefore, they suggested that the higher prevalence of single species infection depends on the order of initiation of infection in the host as the first to infect the host may acquire higher micro-habitat and establishment advantage making less suita- 


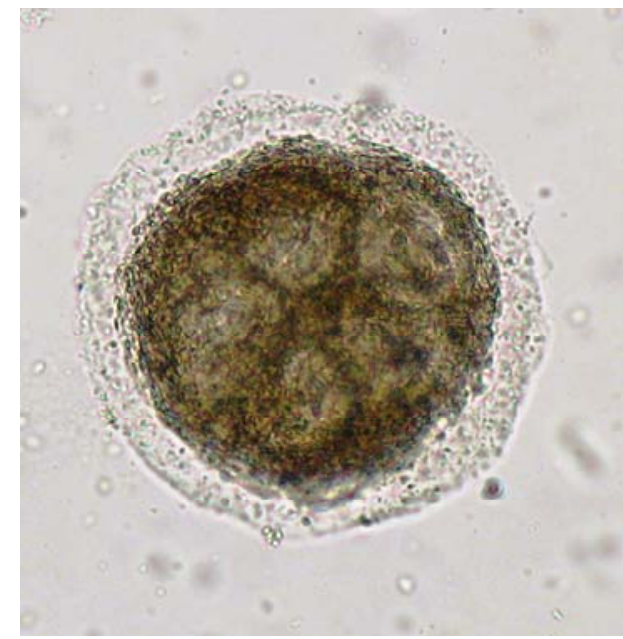

Fig. 4. Typical Raillietina spp. egg capsule of the common pigeon (Columba livia)

ble for late entrants. Also, food preference or higher availability of certain intermediate hosts may influence the establishment of Raillietina species.

Feral pigeons may represent a significant source of infection for domestic or wild birds (Papazachariadou et al., 2008; Gortazar et al., 2010). They share common parasites and they may transfer with their faeces parasite eggs over long distances. Besides the helminths, other parasites or pathogens may also be disseminated to the environment with feral pigeons. Domestic pigeons from Northern Greece were found to be $5.8 \%$ seropositive for Toxoplasma gondii, while no specific antibodies in feral ones were detected (Diakou et al. 2011). The results of a cross-sectional prevalence study carried out by Salant et al. (2009) suggested that pigeons may serve as sentinels for the environmental spread of $T$. gondii. Additionally to parasites, feral pigeons bear the risk of zoonotic transmission of Chlamydia psittaci to humans by close contacts (Geigenfeind et al., 2011). De Sousa et al. (2010) reported that $7.94 \%$ of the tested pigeons transferred Salmonella, including S. typhimurium and S. enteric, $5.5 \%$ were seropositive for Newcastle disease virus and $0.83 \%$ seropositive for $T$. gondii. Furthermore, feral pigeons may pose a considerable health risk to the human population. Consumption of raw or undercooked pigeon meet could be a source for Toxoplasma infection. Breeding and roosting sites of pigeons harbour parasites that may infest humans. Dermatologists should be aware of the possibility of an infestation with ectoparasites deriving from feral pigeons, such as the bedbug Cimex lectularius, the pigeon tick Argas reflexus and the red mite Dermanyssus gallinae (HaagWackernagel et al., 2010). In addition, inhalation of avian antigens in dust and air can cause allergies such as hypersensitivity pneumonitis.

Feral pigeon management programmes and public education should be implemented to reduce the risk of a pigeonto-human or livestock transmission of pathogenic agents and parasites.

\section{Acknowledgements}

The authors would like to acknowledge the Riding Club of Northern Greece for providing the pigeons.

\section{References}

Adang, K. L., OniYe, S. J., Ajanusi, O. J., Ezealor, A. U., ABDU, P. A. (2008): Gastrointestinal helminthes of the domestic pigeons (Columba livia domestica Gmelin, 1789 Aves: Columbidae) in Zaria, Northern Nigeria. Sci. World J., 3(1): $33-37$

AdAng, K. L., OniYe, S. J., EzeAlor, A. U., AbDU, P. A., AJANuSi, O. J., YoriYO, K. P. (2009): Ectoparasites and intestinal helminthes of speckled pigeon (Columba guinea Hartlaub and Finsch 1870) in Zaria, Nigeria. Sci. World J., 4(2): $1-5$

De Sousa, E., Berchieri, A. J., Pinto, A. A., Machado, R. Z., De Carrasco, A. O., Marciano, J. A., Werther, K. (2010): Prevalence of Salmonella spp. antibodies to Toxoplasma gondii, and Newcastle disease virus in feral pigeons (Columba livia) in the city of Jaboticabal, Brazil. J. Zoo Wildl. Med., 41(4): $603-607$

DEDE, P. M., RICHARDS, W. S. (1998): Prevalence of helminthiasis in wild and domestic pigeons from North-east zone of Nigeria. Bull. Anim. Health. Prod. Afr., 46: 193 - 195

DEHLAWI, M. S. (2006): New records of cestodes from birds in Saudi Arabia. Saudi J. Biol. Sci., 13(1): 13 - 16.

Diakou, A., Papadopoulos, E., Antalis, V., Gewehr, S. (2011): Toxoplasma gondii infection in wild and domestic pigeons (Columba livia). In: IV Conference of the Scandinavian-Baltic Society for Parasitology, Oslo, June 19 - 22 2011, Book of abstracts p. 79.

GEIGENFEIND, I., VANROMPAY, D., HAAG-WACKERNAGEL, D. (2012): Prevalence of Chlamydia psittaci in the feral pigeon population of Basel, Switzerland. J. Med. Microbiol., 61: 261 - 265. DOI: 10.1099/jmm.0.034025-0

Ghazi, R. R., Khatoon, N., Mansoor, S., Bilqees, F. M. (2002): Pulluterina karachiensis sp.n. (Cestoda: Anaplocephalidae) from the wild pigeon Columba livia Gmelin. Turk. J. Zool., 26: 27 - 30.

Gortazar, C., Ferroglio, E., Hofle, U., Frolich, K., VICENTE, J. (2007): Diseases shared between wildlife and livestock: a European perspective. Eur. J. Wildl. Res., 53: 241 - 256. DOI: 10.1007/s10344-007-0098-y

HAAG-WACKernagel, D., BIRCHER, A. J. (2010): Ectoparasites from feral pigeons affecting humans. Dermato$\log y, 220(1): 82-92$.

KhaliL, L. F., Jones, A., Bray, R. A. (2006): Keys to the Cestode Parasites of Vertebrates. Oxfordshire: CAB International.

KOzHOKOV, M. K. (2007): Formation of parasite fauna of birds of the North Caucasus. Russ. Agric. Sci., 33(6): $404-$ 407

KuRAmochi, J., InASE, N., TAKayama, K., MiYazaKi, Y., YoshizAWA, Y. (2010): Detection of Indoor and Outdoor Avian Antigen in Management of Bird-Related Hypersen- 
sitivity Pneumonitis. Allergol. Int., 59: 223 - 228. DOI: 10.2332/allergolint.09-OA-0161.

Papazachariadou, M., Diakou, A., Papadopoulos, E. Georgopoulou, I., Komnenou, A., AntoniadouSotiRIADOU, K. (2008): Parasites of the digestive tract in free-ranging birds in Greece. J. Nat. Hist., 42: $381-398$. DOI: $10.1080 / 00222930701835357$

SAlant, H., LANDAU, D. Y., BANETH, G. (2009): A crosssectional survey of Toxoplasma gondii antibodies in Israeli pigeons. Vet. Parasitol., 165(1 - 2): 145 - 149. DOI: 10.1016/j.vetpar.2009.06.031
SoulsBY, E. J. L. (1982): Helminths, arthropods and protozoa of domesticated animals. 8th ed. London: Baillières, Tindall and Cassell.

Torres, J., Foronda, P., Eira, C., Miquel, J., Feliu, C. (2010): Trace element concentrations in Raillietina micracantha in comparison to its definitive host, the feral pigeon Columba livia in Santa Cruz de Tenerife (Canary Archipelago, Spain). Arch. Environ. Contam. Toxicol., 58: 176 - 182. DOI: $10.1007 / \mathrm{s} 00244-009-9352-5$

YamaguTI, S. (1959): Systema Helminthum. Vol. II. Cestodes. New York \& London: Interscience Publishers Inc. 